\title{
Lo importante es participar: El papel de los premios a la calidad en la institucionalización de la evaluación
}

Joaquín Ruiz López

Palabras clave: Reconocimiento, premios a la calidad, autoevaluación organizacional, institucionalización, sistema público de evaluación.

\section{La centralidad de la evaluación}

La evaluación es, como sabemos, una necesidad dialéctica de la gestión. No es posible gestionar racionalmente ni mejorar la gestión sin el conocimiento de lo que se está haciendo y se está logrando. Sin embargo, a pesar de su carácter axiomático —o quizás precisamente por ello— la evaluación necesita instrumentos que contribuyan a su plena implantación, al ejercicio regular de su práctica. Se trata de uno de esos casos en que, aun reconociendo su necesidad esencial, resulta difícil aplicarla de manera sistemática y productiva. La creación de la Agencia Estatal de Evaluación de las Políticas Públicas y de la Calidad de los Servicios abunda justamente en la posición central de la evaluación en el conjunto de las organizaciones públicas, que se ha «convertido en un elemento imprescindible en el diseño y puesta en marcha de cualquier programa o servicio público» (Vanaclocha et al. 2005: 112). La evaluación es una actividad multidisciplinar y los objetos susceptibles de evaluación son diversos, entre ellos, los servicios públicos. «La correspondencia entre un servicio y la unidad u organismo que lo presta puede y suele ser particularmente estrecha y, por tanto, la evaluación de un servicio puede aproximarse metodológicamente a la de aquella, esto es, puede utilizar modelos concebidos en principio para la evaluación de organizaciones (caso típico de los modelos de excelencia)» (Vanaclocha et al. 2005: 118). El propósito de este artículo es mostrar cómo las herramientas de reconocimiento tales como los premios a la calidad fomentan y difunden la práctica de la evaluación en las organizaciones públicas conforme a modelos de referencia y pueden contribuir así a la institucionalización de la evaluación en el ámbito público.

En un trabajo de Elke Löffler publicado en español en 1996 (Löffler 1996), no se reseñaba la existencia de ningún premio a la calidad en el sector público de nuestro país. Únicamente se mencionaba el Premio Príncipe Felipe a la Excelencia Empresarial, que, como se verá más adelante sólo está dirigido al sector privado. Al año siguien-

* Subdirector General de Calidad de los Servicios. Agencia Estatal de Evaluación de las Politicas y la Calidad de los Servicios. 
te se creaban los que quizás sean los primeros premios de este tipo en las Administraciones públicas españolas: los «Premios a la Excelencia y Calidad del servicio público en la Comunidad de Madrid». Desde entonces a la actualidad, una primera y simplificada aproximación puede dar idea de la extensión que han alcanzado hoy en día los programas de premios a la calidad en España. Si tratamos de localizar en un famoso buscador la expresión Premios a la Calidad y Excelencia en la Administración pública española encontraremos alrededor de 40.000 entradas. Naturalmente, no todas ellas hacen referencia estricta a diferentes programas de premios, pero constituyen un indicador de la magnitud que han alcanzado estas iniciativas en los últimos años. Los premios a la calidad constituyen una realidad consolidada que no es posible explicar como un fenómeno meramente mimético o producto de la moda.

\section{Los premios a la calidad}

La figura de los premios a la calidad surge inicialmente en el mundo empresarial con la finalidad de promover la gestión de calidad, a través del reconocimiento de las buenas prácticas. Los premios están vinculados normalmente a unos modelos de referencia que permiten una evaluación homogénea y facilitan las comparaciones y el aprendizaje mutuo (Ruiz 2005a: 241). Los premios se conceden conforme a los criterios de evaluación definidos en el correspondiente modelo de calidad o excelencia y tienen, por tanto, un carácter instrumental, sirviendo para promocionar y difundir modelos comunes de gestión.

Aunque existen premios de este tipo ${ }^{1}$ en numerosísimos países, sólo se comentarán brevemente aquellos que, por la importancia económica de su área de origen o por su interés para España, se han convertido en los cuatro principales premios de referencia internacional: el japonés, el estadounidense, el europeo y el iberoamericano.

\subsection{El premio japonés}

En términos temporales el primer premio a la calidad es el «Premio Deming», creado en Japón en 1951 para galardonar a aquellas empresas (manufactureras o industriales) que se hubieran distinguido en la aplicación del control total de calidad?. Desde su enfoque inicial, los criterios de valoración del «Premio Deming» han evolucionado hasta basarse actualmente en los principios de la Gestión de Calidad Total (GCT), entendiendo por tal el «conjunto de actividades sistemáticas llevadas a cabo por toda la organización para lograr eficaz y eficientemente los objetivos de la misma, así como para proporcionar productos y servicios con un nivel de calidad que satisfaga a los clientes en el tiempo y precio apropiados». El premio está dirigido a las empresas (públicas o privadas) que hayan conseguido mejoras destacadas en su rendimiento mediante la aplicación de la GCT, utilizándose para su comprobación los siguientes «puntos de vista»:

a) Que la organización haya establecido objetivos y estrategias ambiciosos y orientados al cliente bajo un liderazgo claro.

b) Que la GCT haya sido implantada adecuadamente para lograr los objetivos y estrategias del negocio.

c) Que se hayan obtenido los resultados esperados de los objetivos y estrategias de negocio.

${ }^{1}$ El GEM (Global Excellence Models Council) integra a la organizaciones gestoras de los premios más significativos en el mundo: Malcolm Bladrige National Quality Award (EE.UU. www.quality.nist.gov), Business Excellence Australia (www.aqc.org.au), South African Excellence Foundation (www.saef.co.za), European Foundation for Quality Management (www.efqm.org), Singapore Quality Award Management Committee (www.spring.gov.sg), Japan Quality Award Committee (www.jqac.com), Exim Bank Award for Business Excellence (India, www.ciionline.org), Red Iberoamericana de Excelencia-Fundación Iberoamericana para la Gestión de la Calidad (www.fundibeq.org).

${ }^{2}$ www.deming.org/demingprize 
Aunque habitualmente se identifica el «Premio Japonés» con el Deming, también debe mencionarse la existencia de otro premio más reciente. El «Premio Japón a la Calidad» (Japan Quality Award ), establecido en 1995 por el Japan Productivity Center for Socio-Economic Development, está inspirado en el modelo del «Premio Malcolm Baldrige» de Estados Unidos y adaptado a la realidad japonesa. El Premio está dirigido a empresas y, desde 2003, a corporaciones locales, para galardonar la gestión global excelente y la innovación orientada al cliente.

\subsection{El premio estadounidense}

El premio estadounidense, conocido como «Malcolm Baldrige National Quality Award» ${ }^{4}$, fue creado en 1987 con el propósito de mejorar la calidad y la productividad de las empresas norteamericanas mediante el reconocimiento competitivo, el aprendizaje y la emulación y la autoevaluación conforme a directrices y criterios comunes.

El «Premio Malcolm Baldrige» tiene su equivalente para la administración federal en el «Premio Presidencial a la Calidad» (President's Quality Award ${ }^{5}$ ), creado en 1988. Este programa de reconocimiento incluye dos tipos de premio: el «Premio Presidencial a la Calidad» y el «Premio a la Mejora de la Calidad». Aunque ambos se evalúan conforme a los criterios del «Premio Malcolm Baldrige» adaptados al entorno administrativo para promover la cooperación y el intercambio entre las organizaciones públicas y las privadas, tienen distinto objeto. El primero reconoce a las organizaciones que han demostrado madurez en sus enfoques para desplegar un rendimiento excelente en todo su seno. El segundo, galardona a aquellas organizaciones que han demostrado enfoques iniciales positivos para desplegar un rendimiento excelente en varias partes de la organización.

\subsection{El premio europeo}

En 1988 se crea por los presidentes de 14 grandes empresas europeas ${ }^{6}$ la Fundación Europea para la Gestión de Calidad (European Foundation for Quality Management, EFQM) con la misión de «apoyar la gestión de las empresas europeas, así como estimular y, en su caso, prestar asistencia a todos los segmentos de la comunidad europea». De 1988 a 1991 centró sus actividades en el diseño de un modelo (el Modelo EFQM) como marco frente al que evaluar las candidaturas al «Premio Europeo a la Calidad». El primer Premio Europeo (EQA en sus siglas inglesas) se presentó por el Rey de España en el curso del Fórum EFQM celebrado en Madrid en 1992. Inicialmente concebido para grandes empresas, el premio se abrió a partir de 1995 al sector público y a las PYMEs. Actualmente cuenta con las siguientes categorías: Grandes Empresas y Unidades de Negocio, PYMEs independientes, PYMEs subsidiarias y Sector Público. Para cada categoría existen cuatro niveles de reconocimiento:

- Ganadores del Premio (Award Winners), organizaciones excepcionales, modélicas a escala europea o global en sus enfoques y sus resultados.

\footnotetext{
${ }^{3}$ www.jqac.com

${ }^{4}<$ www.quality.nist.gov>

${ }^{5}<$ www.opm.gov/quality/>

${ }^{6}$ Bosch, BT, Bull, Ciba-Geigy, Dassault, Electrolux, Fiat, KLM, Nestlé, Olivetti, Philips, Renault, Sulzer y Volkswagen. Inmediatamente después se unieron otras 53 empresas como cofundadoras.
} 
- Ganadores de Menciones (Prize Winners), organizaciones que destacan en uno o más de los ocho conceptos fundamentales de la excelencia ${ }^{7}$.

- Finalistas, organizaciones que han demostrado un alto grado de excelencia en la gestión de sus procesos de mejora continua.

- Reconocimientos a la Excelencia (Recognised for Excellence), organizaciones que han obtenido una puntuación por encima de 400 sobre la máxima de 1000 puntos del Modelo EFQM.

En las trece ediciones del Premio se ha concedido casi un centenar de galardones en sus distintos niveles y categorías, diez de ellos a organizaciones españolas. En la actualidad, EFQM cuenta con 24 organizaciones nacionales asociadas (National Partner Organisatios) y 800 socios. Desde 1998 se han otorgado 11 galardones a organizaciones del sector público ${ }^{8}$.

\subsection{El Premio Iberoamericano}

La Fundación Iberoamericana para la Gestión de la Calidad (FUNDIBEQ) se crea en 1998 bajo los auspicios de la VIII Cumbre Iberoamericana de Jefes de Estado y de Gobierno con los objetivos de diseñar un Modelo Iberoamericano de Excelencia en la Gestión y definir las bases de los Premios Iberoamericanos de la Calidad'. Actualmente su patronato está integrado por 15 organizaciones y cuenta con más de 50 miembros asociados, así como con organizaciones colaboradoras (ONAs) en Argentina, Brasil, Chile, Colombia, Cuba, México, Paraguay, Perú, Portugal, Uruguay y España. En 1999 se consensuó entre representantes de 17 países iberoamericanos el Modelo Iberoamericano de Excelencia en la Gestión así como las bases del «Premio Iberoamericano de la Calidad», convocándose su primera edición en el año 2000. Al igual que el Modelo EFQM, en el que en gran medida está inspirado, se compone de nueve criterios de evaluación, y cuenta con seis categorías (organizaciones privadas grandes, medianas y pequeñas y organizaciones públicas grandes, medianas y pequeñas). En 2003 se constituyó la Red Iberoamericana de la Excelencia en la Gestión (REDIBEX) que integra, junto con FUNDIBEQ, a las organizaciones gestoras de los premios nacionales de diez países iberoamericanos. El Modelo Iberoamericano también dispone de una adaptación a la Administración pública realizada por el Ministerio de Administraciones Públicas ${ }^{10}$ (Ruiz 2005b).

En el cuadro 1 se ofrece una comparación esquemática entre los modelos que sustentan a los cuatro premios reseñados.

\footnotetext{
${ }^{7}$ Orientación hacia los resultados, orientación al cliente, liderazgo y coherencia, gestión por procesos y hechos, desarrollo e implicación de las personas, proceso continuo de aprendizaje, innovación y mejora, desarrollo de alianzas y responsabilidad social de la organización.

${ }^{8}$ AVE-RENFE (España), Inland Revenue Cumbernauld (Reino Unido), Arbejdsformidlingen-Ringkoebing AMT (Dinamarca), Foxdenton School and Integrated Nursery (Reino Unido), St. Mary's College Northern Ireland (Reino Unido), Customs and Tax Region Aarbus (Dinamarca), Runshaw College (Reino Unido), Kocaeli Chamber of Industry (Turquía), Colegio Ursulinas (España).

${ }^{9}<$ www.fundibeq.org>

${ }^{10}$ Guía de Autoevaluación para la Administración Pública. Modelo Iberoamericano de Excelencia en la Gestión. Madrid, MAP-FIIAPP, 2003
} 


\begin{tabular}{|c|c|c|c|c|}
\hline 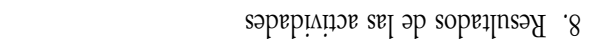 & 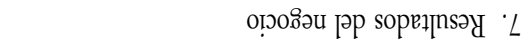 & 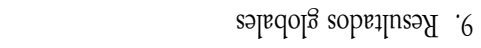 & 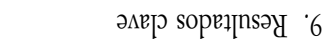 & \multirow{11}{*}{ SOIУGLIYว } \\
\hline 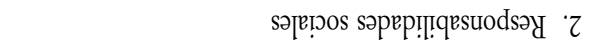 & & рерәэюs әр sорет[nsәу '8 & 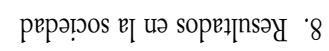 & \\
\hline & & seuos.əd se & 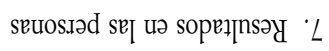 & \\
\hline & & 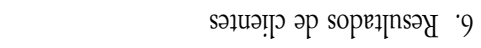 & 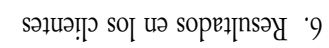 & \\
\hline 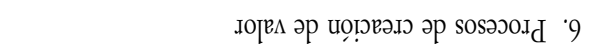 & 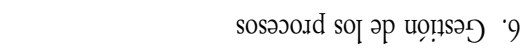 & & SOsəz力口, $\mathrm{A}$ & \\
\hline 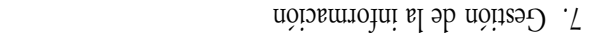 & 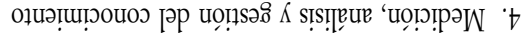 & & & \\
\hline 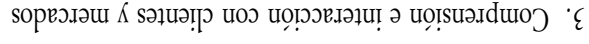 & 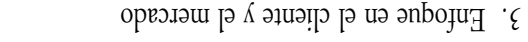 & 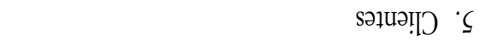 & & \\
\hline & & sopẹpose $\alpha$ sos.ñ & 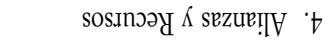 & \\
\hline 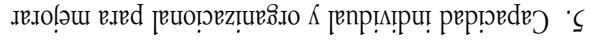 & 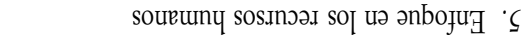 & 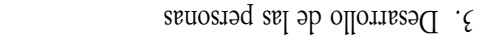 & 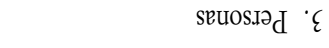 & \\
\hline 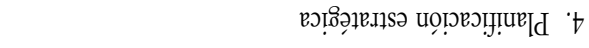 & 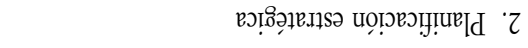 & 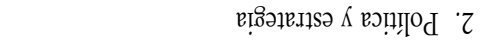 & 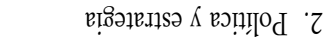 & \\
\hline 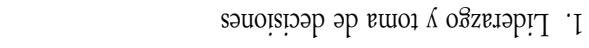 & 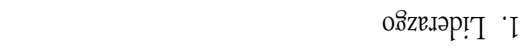 & 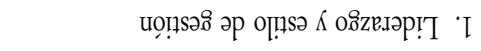 & 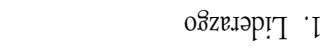 & \\
\hline (uode $[$ ) כHOI & (กП’⿱一𫝀日) VONGW & 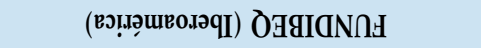 & (вdo.ng) КӦН & \\
\hline
\end{tabular}

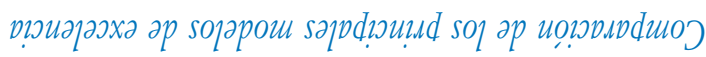

I очđ७กว 


\section{Los premios a la calidad en España}

En 1993 se crean los «Premios Príncipe Felipe a la Excelencia Empresarial» ${ }^{11}$ con la finalidad de fortalecer la competitividad de las empresas españolas y su acceso a nuevos mercados. Se convocan anualmente por el Ministerio de Industria. Según la última edición, la número once (2006-2007) tiene las siguientes categorías o modalidades:

- Diseño.

- Energías renovables y eficiencia energética.

- Internacionalización.

- Excelencia Turística.

- Calidad Industrial.

- Innovación tecnológica (PYME y grandes empresas).

- Sociedad de la Información y tecnología de la información y las comunicaciones.

- Gestión de la marca renombrada.

- Competitividad empresarial en PYME y gran empresa.

Pueden participar empresas con mayoría de capital privado no premiadas en las dos ediciones anteriores, siendo evaluadas las candidaturas conforme a criterios de la norma ISO 9001:2000 y del Modelo Europeo de Calidad Total para PYME ${ }^{12}$.

Además de los anteriores, que son de ámbito nacional, existen también premios de carácter regional, entre los que se pueden mencionar el «Premio a la Excelencia Empresarial en Aragón», convocado por el Instituto Aragonés de Fomento y la Agencia de Desarrollo Regional, el «Premio Asturias a la Calidad Empresarial», convocado por el Instituto de Desarrollo Económico del Principado de Asturias, el «Premio a la Calidad de la Generalitat de Cataluña», convocado por el Centro de Innovación y Desarrollo Empresarial, el «Premio Balear a la Excelencia en la Gestión», convocado por el Instituto de Innovación Empresarial y el «Premio Vasco a la Calidad en la Gestión», convocado por la Fundación Euskalit ${ }^{13}$.

\section{Los premios en el sector público}

Es significativo que los estados miembros de la OCDE, al abordar en el curso de los dos últimos decenios programas de modernización de sus administraciones públicas tendentes a la mejora de la eficiencia y al incremento de la orientación al ciudadano, hayan coincidido en la introducción de conceptos de gestión como la calidad y en la utilización de herramientas como las evaluaciones basadas en modelos de excelencia y los concursos o premios a la calidad.

\footnotetext{
${ }^{11}<$ www.mityc.es/principefelipe>

${ }^{12}$ Elaborado por la Fundación Europea para la Gestión de Calidad (EFQM) y la Organización Europea para la Calidad (EOQ).

${ }^{13}<$ www.iaf.es>; <www.idepa.es>; <www.cidem.com/cidem/cat.serveis>;<www.idi.es>; <www.euskalit.net>
} 
Los premios a la calidad en el sector público se transfirieron, como otras tantas iniciativas, desde el sector privado, dentro del cambio de paradigma de gestión experimentado en las administraciones públicas contemporáneas. Estos premios tienen tres finalidades básicas. En primer lugar, la motivación de los gestores públicos por la calidad a través de un sucedáneo de la competencia en un contexto en el que no existe competencia. En segundo lugar, la posibilidad de medir la calidad mediante indicadores multidimensionales en ausencia de un indicador sintético como es el precio. Y en tercer lugar, la ayuda a la mejora mediante el aprendizaje mutuo o benchlearning (Löffler 1996: 37). Puede decirse, por tanto, que los premios en el sector público combinan dos elementos aparentemente contradictorios como son la competición y la colaboración, aunque en realidad tratan de fomentar la segunda a través de la primera.

Prácticamente todos los países de la OCDE y de la Unión Europea disponen de programas de premios a la calidad en el sector público. En los trabajos de Elke Löffler se realiza un examen pormenorizado de los premios en los países de la OCDE, mientras que Engel (Engel 2003: 29-37) se ocupa de los países de la última ampliación de la UE. En el cuadro 2 se reflejan los estados que cuentan con un programa de premios específico para el sector público y los que cuentan con un premio a la calidad abierto indistintamente a organizaciones públicas y privadas.

\section{CUADRO 2}

Los premios en el sector público

\begin{tabular}{|l|l|l|}
\hline \multicolumn{1}{|c|}{ PAÍS } & PREMIO PARA SECTOR PÚBLICO & PREMIO ABIERTO A PRIVADO Y PÚBLICO \\
\hline Alemania & Speyer Quality Award & \\
\hline Australia & - & Australian Quality Awards \\
\hline Austria & Speyer Quality Award & \\
\hline Bélgica & Quality Conference for the Public Sector & Premio Belga a la Calidad \\
\hline Canadá & IAPAC Award for Innovative Management & Canada Awards for Excellence \\
\hline CAPAM International Innovations Awards & \\
\hline Eslovaquia & De Bedste i Staten & Danish Quality Award \\
\hline Eslovenia & & Slovak National Quality Award \\
\hline España & Premios a la Calidad e Innovación en la Gestión Pública & Business Excellence Prize of the Republic of Slovenia \\
\hline Estados Unidos & President's Awards & \\
\hline Estonia & & Estonian National Quality Award Contest \\
\hline Finlandia & Bra Serviceverk & Finnish Quality Award \\
\hline Francia & & \\
\hline Grecia & Hellenic Quality Award System & \\
\hline Islandia & & Iceland Quality Award \\
\hline Italia & Premio Innovazione nella Pubblica Amministrazione & \\
\hline Japón & & Japan Quality Award \\
\hline Letonia & & Latvian National Quality Award \\
\hline México & & Premio Nacional a la Calidad \\
\hline Noruega & Vellykket forvaltning & \\
\hline Nueva Zelanda & & New Zealand National Quality Awards \\
\hline Polonia & Most Friendly Office of Government Administration & Polish Quality Award \\
\hline Portugal & & Premio Excelencia IPQ \\
\hline Reino Unido & Sello de la Carta & UK Quality Award \\
\hline República Checa & & Czech Republic National Quality Award \\
\hline Suecia & Kronorna bland verken & Swedish Quality Award \\
\hline Suiza & Speyer Quality Award & \\
\hline
\end{tabular}

Fuente: Löffler (1996) Engel (2003) y MAP 
La relevancia que iban adquiriendo los premios en la agenda de las políticas administrativas se puso de manifiesto cuando, por acuerdo de la XXVIII Reunión de Directores Generales responsables de administración pública de los países miembros de la Unión Europea, se constituye en 1998 el Grupo de Servicios Públicos Innovadores (IPSG) con el objetivo inicial de estudiar la creación de un premio a la calidad en las administraciones públicas europeas. Dado que no hubo consenso sobre la oportunidad y el modelo de evaluación aplicable al premio, se optó por trabajar en el diseño de un Marco Común de Evaluación (CAF) para las administraciones públicas europeas, entendiendo que lo primordial era establecer un marco de referencia compartido por todos los países y que eventualmente sirviera de base para un futuro próximo. Con todo, esto no desvirtúa el enfoque inicial hacia las fórmulas competitivo-cooperativas. Si bien hasta la fecha no se ha creado ni convocado un premio a las administraciones públicas europeas, el mencionado $C A F$ está siendo utilizado como base para algunos premios nacionales o regionales como el Speyer. Asimismo puede mencionarse, como indicador de la asunción de la cultura de premios, la iniciativa lanzada en 2004 por EFQM y patrocinada por tres firmas consultoras del «Premio EFQM para la Administración Local y Regional» con la finalidad de reconocer la excelencia operacional de las administraciones locales y regionales, principalmente en el diseño e implementación de soluciones de e-administración.

\section{Los premios en las Administraciones públicas españolas}

Dentro del sector público español existen premios en diferentes administraciones autonómicas, en la Administración General del Estado y uno que está abierto a todos los niveles de gobierno (estatal, autonómico y local) ${ }^{14}$. Los premios en las administraciones autonómicas y estatal están convocados por el respectivo departamento responsable en materia de administración pública, mientras que el premio «abierto» mencionado en tercer lugar (Ciudadanía) está convocado por una organización sin ánimo de lucro denominada Observatorio para la Calidad de los Servicios Públicos. En el cuadro 3 se ofrece una panorámica de los premios en las administraciones públicas españolas.

CUADRO 3

Los Premios en las Administraciones Públicas Españolas

\begin{tabular}{|c|c|c|c|c|c|}
\hline Ámbito premio & Creación & Periodicidad & Modalidades & $\begin{array}{l}\text { Criterios } \\
\text { Evaluación }\end{array}$ & Contenido \\
\hline $\begin{array}{l}\text { Administración General del Estado: } \\
\text { «Premios a la Calidad y a las } \\
\text { Mejores Prácticas en la AGE» }\end{array}$ & 1999 & Anual & $\begin{array}{l}\text { 1. Premio a la Calidad } \\
\text { 2. Premios a las Mejores } \\
\text { Prácticas }\end{array}$ & $\begin{array}{l}\text { EFQM } \\
\text { - Receptividad y } \\
\text { Compromiso } \\
\text { - Alianzas y Recursos } \\
\text { - Participación } \\
\text { - Innovación y } \\
\text { aprendizaje } \\
\text { - Resultados }\end{array}$ & $\begin{array}{l}\text { - Placa y Diploma } \\
\text { - Placa y Diploma }\end{array}$ \\
\hline $\begin{array}{l}\text { Comunidad de Madrid } \\
\text { «Premio a la Excelencia y } \\
\text { Calidad del Servicio Público } \\
\text { en la Administración } \\
\text { de la Comunidad de Madrid» }\end{array}$ & 1997 & Anual & Única & EFQM & Escultura y Certificado \\
\hline
\end{tabular}

${ }^{14}$ El Real Decreto 951/2005, de 29 de julio, por el que se establece el marco general para la mejora de la calidad en la Administración General del Estado, crea en su artículo 24 los Premios a la Calidad e Innovación en la Gestión Pública, que están abiertos a la participación de todas las administraciones públicas. Por orden ministerial de 14 de febrero de 2006 se regularon dichos premios y se efectuó la convocatoria correspondiente. 
CUADRO 3 (Cont.)

Los Premios en las Administraciones Públicas Españolas

\begin{tabular}{|c|c|c|c|c|c|}
\hline Ámbito premio & Creación & Periodicidad & Modalidades & $\begin{array}{l}\text { Criterios } \\
\text { Evaluación }\end{array}$ & Contenido \\
\hline $\begin{array}{l}\text { Junta de Castilla y León } \\
\text { «Premios a la Calidad y } \\
\text { Modernización de la Administración } \\
\text { de Castilla y León» }\end{array}$ & 2002 & Anual & $\begin{array}{l}\text { 1. Excelencia y Calidad } \\
\text { 2. Mejores Prácticas } \\
\text { Admón. Autonómica } \\
\text { 3. Mejores prácticas } \\
\text { administraciones } \\
\text { en Castilla y León }\end{array}$ & $\begin{array}{l}\text { EFQM } \\
\text { REDER }^{15} \\
\text { REDER }\end{array}$ & $\begin{array}{l}\text { - Dotación económica, } \\
\text { Escultura, Diploma, } \\
\text { Placa Exterior } \\
\text { - Dotación económica, } \\
\text { Diploma y Placa } \\
\text { exterior }\end{array}$ \\
\hline $\begin{array}{l}\text { Junta de Andalucía } \\
\text { «Premios a la Calidad } \\
\text { de los Servicios Públicos } \\
\text { y Administración Electrónica } \\
\text { de la Junta de Andalucía» }\end{array}$ & 2004 & Anual & $\begin{array}{l}\text { 1. Excelencia de los } \\
\text { Servicios Públicos } \\
\text { 2. Mejores Prácticas } \\
\text { Calidad } \\
\text { 3. Mejores Prácticas } \\
\text { e-administración }\end{array}$ & $\begin{array}{l}\text { REDER } \\
\text { EFQM }\end{array}$ & $\begin{array}{l}\text { - Escultura, Diploma } \\
\text { y Placa } \\
\text { - Diploma y placa }\end{array}$ \\
\hline $\begin{array}{l}\text { Junta de Castilla-La Mancha } \\
\text { «Premio a la Excelencia y Calidad } \\
\text { de los servicios públicos } \\
\text { en Castilla-La Mancha» }\end{array}$ & 2003 & Anual & Única & $\begin{array}{l}\text { - Transparencia y } \\
\text { accesibilidad } \\
\text { - Participación } \\
\text { - Cooperación } \\
\text { - Innovación } \\
\text { - Resultados }\end{array}$ & $\begin{array}{l}\text { Certificado y curso } \\
\text { de formación }\end{array}$ \\
\hline $\begin{array}{l}\text { Observatorio para la Calidad } \\
\text { de los Servicios Públicos } \\
\text { (nacional) } \\
\text { «Premio Ciudadanía» }\end{array}$ & 1999 & Bienal & Única & $\begin{array}{l}\text { - Planificación y } \\
\text { Liderazgo } \\
\text { - Recursos } \\
\text { - Efectos } \\
\text { - Procesos } \\
\text { - Comunicación }\end{array}$ & Escultura y diploma \\
\hline
\end{tabular}

\section{La experiencia de la Administración General del Estado}

El Real Decreto 1259/1999 de 16 de julio, por el que se regulan las Cartas de Servicios y los Premios a la calidad en la Administración General del Estado, crea en su capítulo IV los «Premios a las Mejores Prácticas» y el «Premio a la Calidad» con una doble finalidad. Por una parte, la de fomentar la emulación y el aprendizaje mutuo; y, por otra, la de formalizar el reconocimiento al esfuerzo personal y colectivo para mejorar el funcionamiento de las organizaciones y la calidad de sus servicios. Esta doble finalidad se expresaba igualmente en el Libro Blanco para la Mejora de los Servicios Públicos, al señalar que: «Ligado a la acción de aprender de los mejores se encuentra el establecimiento de premios de excelencia (...) Los premios constituyen un reconocimiento y un estímulo. Sirven para la valoración de aquellas personas y unidades que se han comprometido con los ciudadanos en la prestación de un servicio de calidad y que se han preocupado seriamente por obtener los resultados que los ciudadanos esperan de ellos. El reconocimiento ante la sociedad es una fuente de motivación para las personas, les indican que su esfuerzo se ve recompensado, que han seguido el camino adecuado y que han de continuar por esa vía para mantener el prestigio conseguido.» (MAP 2000: 78). Los premios no constituyen, por tanto, una iniciativa aislada sino que se conciben, desde un enfoque sistémico, como complemento natural a los programas de Cartas de Servicios y de Autoevaluación de las organizaciones, como se muestra en la matriz de procesos del cuadro 4 (Ruiz 2003: 39).

\footnotetext{
${ }^{15}$ Siglas de Resultados, Enfoque, Despliegue, Evaluación y Revisión.
} 


\begin{tabular}{|c|c|c|c|c|c|c|c|c|}
\hline 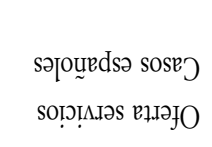 & 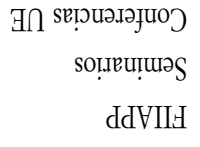 & 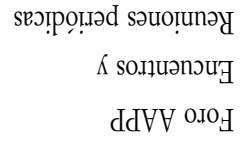 & 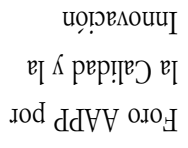 & & $\begin{array}{r}\text { ершешәр } \\
\text { e WOL sosinj }\end{array}$ & 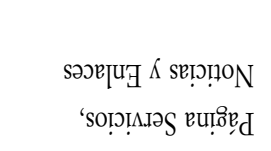 & & uọpowoxd \\
\hline SEבIEว PInY & & & 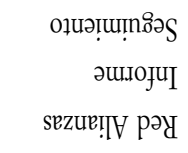 & & 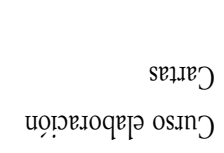 & 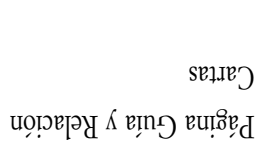 & 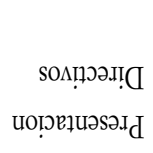 & sełdeJ \\
\hline $\begin{array}{r}\text { sоәр! } \Lambda \\
\text { soıq!T } \\
\text { sоџәाОН }\end{array}$ & 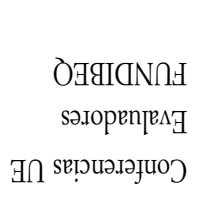 & soḷmid soito & 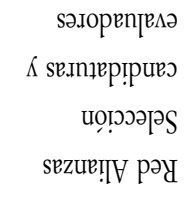 & 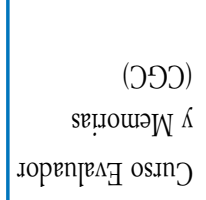 & & 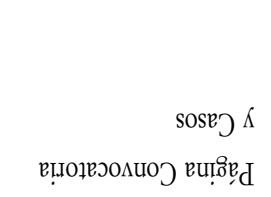 & $\begin{array}{l}\text { вədoIng } \\
\text { вuвwวS }\end{array}$ & so!mळə, $\mathbf{d}$ \\
\hline 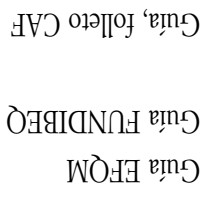 & 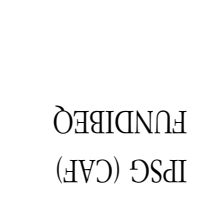 & 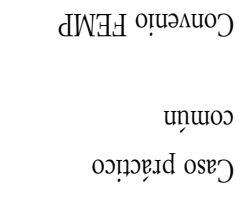 & $\begin{array}{l}\text { so[00010.Id } \\
\text { sezue!f pәy }\end{array}$ & & $\begin{array}{l}\text { ㅂJ osinj - } \\
\text { WÖнᄏ̈ osinj - }\end{array}$ & 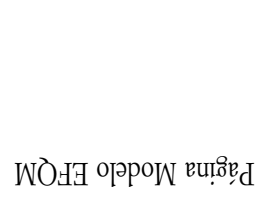 & 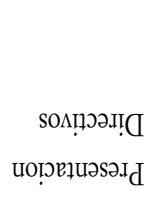 & 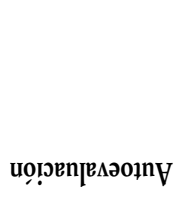 \\
\hline & роиюэрииәти I & $\begin{array}{l}{ }^{D 00} \mathrm{~T} \cdot \mathrm{V} \\
\ltimes \forall \forall \cdot \supset \supset\end{array}$ & GЭV & 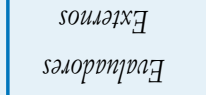 & 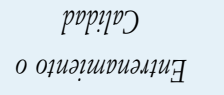 & $q^{2} \mathrm{MI}$ & plovuasald & \\
\hline 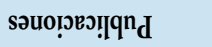 & & 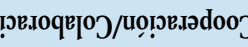 & & & $\mathrm{w.tO}_{\mathrm{H}}$ & 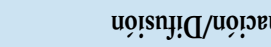 & ојण & \\
\hline
\end{tabular}

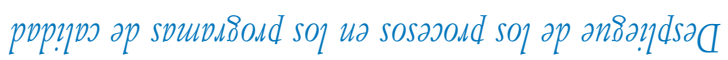

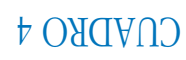


La creación de dos tipos de premios - mejores prácticas y calidad — responde a una diferencia básica entre ambos. Mientras que en los primeros las candidaturas objeto de evaluación hacen referencia a «proyectos», en el segundo se refieren a «organizaciones». Los premios a las mejores prácticas galardonan, tras su evaluación, un proyecto específico o una parte de una organización, mientras que el premio a la calidad evalúa el rendimiento global de una organización (Löffler 2001: 31-33). Los primeros están concebidos para concitar la máxima participación de organizaciones con un incipiente nivel de madurez en gestión de calidad y que se desenvuelven en un entorno con alto grado de «publicismo» 0 «administrativismo» ${ }^{16}$. En cambio, el segundo está dirigido a aquellas organizaciones públicas ya iniciadas en la gestión de calidad o que operan en un marco más gerencial o de tipo mercado. Por la propia naturaleza de unos y otros premios, los criterios de evaluación han de ser distintos, siendo más globalizantes los del premio a la calidad, que hacen referencia a toda la organización como sistema de entradas y salidas.

\subsection{Los Premios a las Mejores Prácticas}

La 1. 'edición de los «Premios a las Mejores Prácticas en la Administración General del Estado» se convoca por Orden del Ministro de Administraciones Públicas de 25 de enero de 2000 con el fin de reconocer las iniciativas de los órganos y organismos de la Administración General del Estado para mejorar la calidad de sus servicios. Las sucesivas ediciones han sido convocadas en julio de 2001, octubre de 2002 y octubre de $2003^{17}$.

Los premios, consistentes en una placa y un diploma acreditativo, no tienen un número limitado, si no que pueden concederse tantos como candidaturas estime el jurado que reúnen los méritos suficientes para ello en función del número de las mismas y de los resultados de la evaluaciones. Estos premios están dirigidos a los órganos de la Administración General del Estado, los organismos autónomos vinculados o dependientes de la misma, las entidades gestoras y servicios comunes de la Seguridad Social y otros organismos públicos que se encuentren en el ámbito de aplicación de la Ley de Organización y Funcionamiento de la Administración General del Estado. Pueden presentarse candidaturas relativas a las prácticas de buena gestión consistentes en experiencias o proyectos consolidados e implantados, cuyos resultados estén redundando en un superior rendimiento de la organización y una mayor calidad de los servicios. Las candidaturas deben formalizarse en una memoria descriptiva de la iniciativa, de un máximo de cuarenta páginas, y son valoradas de acuerdo con los siguientes criterios:

1. Receptividad y compromiso.

2. Participación.

3. Gestión de recursos y alianzas.

4. Innovación.

5. Resultados globales y satisfacción del usuario.

Tras una preselección de las Subsecretarías de los Departamentos a los que pertenecen las distintas organizaciones candidatas, la Dirección General de Inspección, Evaluación y Calidad de los Servicios del Ministerio de Administraciones Públicas ${ }^{18}$ evalúa los actividades y logros de las candidaturas en cada uno de los criterios antes mencionados empleando el sistema de medida basado en la lógica REDER que figura en los cuadros 5.1 y 5.2.

\footnotetext{
${ }^{16}$ Esta expresión se correspondería con el término inglés publicness, que hace referencia al carácter más anclado en los valores específicos del Derecho Público frente a los de la gerencia y el mercado.

${ }^{17}$ Las bases de las convocatorias han experimentado ligeras modificaciones a lo largo de las cuatro ediciones. Aquí se recogen las correspondientes a la $4 .^{\text {a }}$ y última edición.

${ }^{18}$ Dirección General suprimida por Real Decreto 9/2007, de 12 de enero.
} 
CUADRO 5.1

Tabla de puntuación para los criterios 1, 2, 3 y 4 (Receptividad y compromiso, Participación, Gestión de recursos y alianzas, Innovación)

\begin{tabular}{|l|l|c|}
\hline \multicolumn{1}{|c|}{ Calificación } & \multicolumn{1}{c|}{ Comentarios ilustrativos } & Puntuación \\
\hline Criterio no desarrollado o desarrollado de manera inadecuada & $\begin{array}{l}\text { - No existe evidencia al respecto } \\
- \text { Se detecta alguna idea o intención } \\
- \text { Si existe, sólo es aplicable en una minoría de áreas }\end{array}$ & 0 \\
\hline Criterio parcialmente desarrollado & $\begin{array}{l}\text { - Inicio reciente } \\
- \text { Alguna evidencia parcialmente documentada } \\
- \text { Implantación extensiva a algunas áreas } \\
- \text { Revisiones ocasionales }\end{array}$ & 25 \\
\hline Criterio bastante desarrollado & $\begin{array}{l}\text { - Evidencia clara y documentada } \\
- \text { Implantación extensiva a la mayoría de áreas } \\
- \text { Revisiones regulares }\end{array}$ & 50 \\
\hline Criterio ampliamente desarrollado & $\begin{array}{l}\text { - Evidencia clara y plenamente documentada } \\
- \text { Implantado en todas las áreas relevantes } \\
- \text { Revisiones regulares }\end{array}$ & 75 \\
\hline Criterio desarrollado en su totalidad & $\begin{array}{l}\text { - Evidencia clara y plenamente documentada } \\
- \text { Implantación en todas las áreas } \\
- \text { Revisiones sistemáticas en un ciclo de mejora continua } \\
- \text { Aplicación en otras organizaciones }\end{array}$ & 100 \\
\hline
\end{tabular}

\section{CUADRO 5.2}

Tabla de puntuación para el criterio 5 (Resultados)

\begin{tabular}{|l|l|c|}
\hline \multicolumn{1}{|c|}{ Calificación } & \multicolumn{1}{c|}{ Comentarios ilustrativos } & Puntuación \\
\hline Sin datos; tendencias negativas & $\begin{array}{l}\text { - Resultados anecdóticos o casuales } \\
- \text { No se han medido o no desconocen }\end{array}$ & 25 \\
\hline Cierta mejora & $\begin{array}{l}\text { - Mayoría de resultados mediocres con algunos } \\
\text { buenos aislados } \\
\text { Resultados con tendencia a mejorar durante algunos años }\end{array}$ & $\begin{array}{l}\text { - Resultados buenos y tendencia en progresión los tres } \\
\text { últimos años }\end{array}$ \\
\hline Resultados buenos en la mayoría de las áreas & $\begin{array}{l}\text { - Tendencia en progresión en los últimos 3-5 años } \\
- \text { Los resultados alcanzan los objetivos fijados }\end{array}$ & 50 \\
\hline Resultados excelentes & $\begin{array}{l}\text { - Resultados excelentes en comparación con otras } \\
\text { organizaciones } \\
- \text { Tendencia en progresión sostenida los últimos } 5 \text { años }\end{array}$ & 75 \\
\hline
\end{tabular}

El fallo sobre las candidaturas ganadoras corresponde a un Jurado designado por el Ministro de Administraciones Públicas entre personas de reconocida experiencia en la Administración o en la gestión de calidad ${ }^{19}$.

${ }^{19}$ La presidencia del jurado en las sucesivas ediciones la ha ostentado el titular de la Secretaría de Estado de Organización Territorial o de la Subsecretaría de Administraciones Públicas, los vocales representaban en el máximo nivel a entidades del mundo de la calidad, como la Asociación Española para la Calidad o el Club Gestión de Calidad, a Universidades y a grandes empresas privadas y públicas. El Director General de Inspección, Evaluación y Calidad de los Servicios ha actuado como secretario, con voz y voto, en las cuatro ediciones. 
Además del galardón en sí mismo, las organizaciones ganadoras pueden beneficiarse de los siguientes efectos:

- Hacer constar en sus publicaciones y material impreso, durante los tres años siguientes, la circunstancia de haber obtenido el premio, así como anunciarlo en sus instalaciones por tiempo indefinido.

- Otorgar reconocimiento al personal participante en la iniciativa y, en todo caso, anotarlo en su Hoja de Servicios.

- Recibir un informe detallado de los resultados de su evaluación, así como orientación para acometer futuras acciones de mejora.

- La posibilidad de que la participación del personal de la organización receptora del premio en las acciones conducentes a la obtención del mismo sea tenida en cuenta por los órganos competentes a efectos de la retribución por el complemento de productividad, de acuerdo con la normativa de aplicación.

- Obtener facilidades para asistir a cursos, conferencias o jornadas en materia de calidad organizados por el Ministerio de Administraciones Públicas.

Por su parte, las organizaciones premiadas se comprometen a participar en las acciones de difusión organizadas por el Ministerio de Administraciones Públicas y a autorizar la publicación de sus memorias de presentación.

A la 1. ${ }^{a}$ edición se presentaron 21 candidaturas de organizaciones encuadradas en ocho Ministerios, 12 de las cuales resultaron premiadas por Orden del Ministro de Administraciones Públicas de 16 de mayo de 2001 (MAP 2002a: 41-43). A la 2. ${ }^{a}$ edición concurrieron 40 candidaturas de organizaciones encuadradas en seis Ministerios, de las que fueron galardonadas 15 (OM de 6-5-02) (MAP 2002b: 64-67). La 3. ${ }^{a}$ edición contó con la participación de 63 candidaturas, presentadas por organizaciones dependientes de 12 ministerios, premiándose por Orden de 16 de julio de 2003 a 12 de ellas (MAP 2004: 56-62). La 4. ${ }^{a}$ edición de los «Premios a las Mejores Prácticas» contó con la concurrencia de 47 candidaturas, siendo premiadas 12 de ellas (MAP 2005: 34-39). En el gráfico 1 se muestra la evolución en la participación.

\section{GRÁFICO 1}

\section{Evolución de la participación premios mejores prácticas}

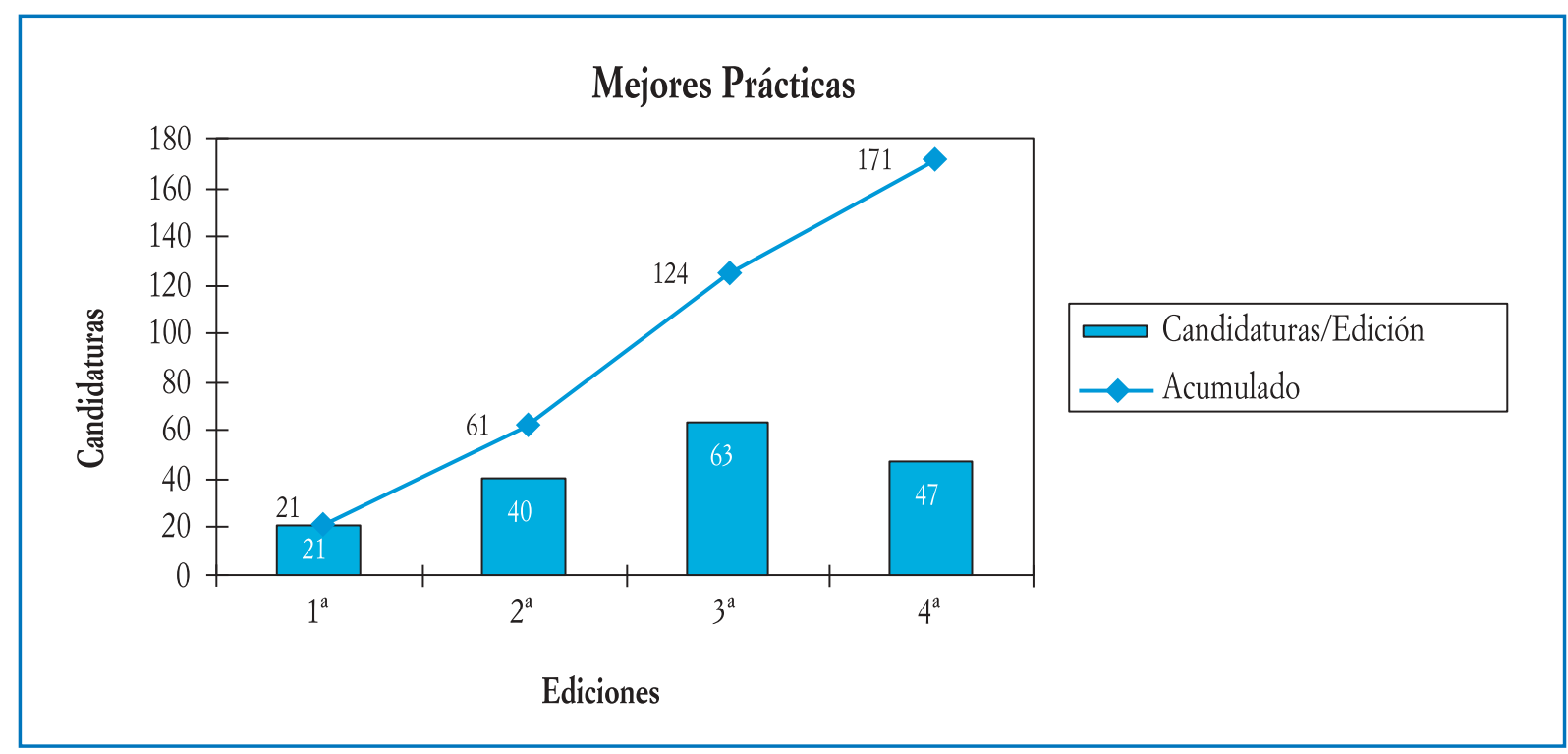




\subsection{El Premio a la Calidad}

Las cuatro ediciones del «Premio a la Calidad en la Administración General del Estado» se convocan en las mismas fechas que los de Mejores Prácticas, con el fin de reconocer al órgano y organismo que se haya distinguido muy especialmente en el incremento de la calidad de sus servicios y que cumpla el requisito de tener aprobada su Carta de Servicios. El Premio es único y consiste en una placa y un diploma acreditativo, si bien pueden otorgarse menciones honoríficas a otras candidaturas que a juicio del Jurado reúnan méritos suficientes para ello.

Las candidaturas deben formalizarse mediante una memoria con un máximo de 75 páginas describiendo el funcionamiento de la organización candidata conforme al Modelo EFQM de Excelencia en su adaptación a la Administración pública ${ }^{20}$. La valoración de las candidaturas se realiza por equipos de evaluación integrados por funcionarios y expertos en el Modelo EFQM designados por el Director General de Inspección, Evaluación y Calidad de los Servicios, de entre quienes estuvieran acreditados como evaluadores por el Club Gestión de Calidad (actualmente Club Excelencia en Gestión), representante en España de la Fundación Europea para la Gestión de Calidad (EFQM). Este último aspecto es importante de destacar, ya que para dotar de credibilidad y solvencia técnica al proceso de evaluación, en enero de 2000 se suscribió un Convenio Marco de Colaboración entre el Ministerio de Administraciones Públicas y el Club Gestión de Calidad que, entre otras cosas, ha permitido que, a lo largo de estos años, 175 funcionarios adquiriesen la condición de evaluadores EFQM acreditados y que el jurado del premio estuviera compuesto mayoritariamente por personalidades del ámbito de la empresa y de la gestión de calidad ${ }^{21}$.

Los compromisos de las organizaciones galardonadas y los efectos del premio son prácticamente iguales a los de mejores prácticas, aunque existe una especificidad importante en el de calidad. A partir de la 3. a edición, las organizaciones candidatas que en su evaluación hayan obtenido unos resultados superiores a los 200 puntos pueden solicitar al Club Excelencia en Gestión la iniciación del proceso de tramitación del Sello de Excelencia en sus diferentes categorías, conforme a las puntuaciones acreditadas por la Dirección General de Inspección, Evaluación y Calidad de los Servicios, siendo convalidable dicho sello, si la organización candidata así lo solicita, con el correspondiente nivel europeo de los Levels of Excellence de la Fundación Europea para la Gestión de Calidad (EFQM).

A la 1. a edición se presentaron seis candidaturas, concediéndose el «Premio a la Dirección Provincial del Instituto Nacional de la Seguridad Social» en Guipúzcoa (MAP 2002a: 19-21). En la 2. ${ }^{a}$ edición del «Premio a la Calidad» se incrementó la participación hasta 10 candidaturas, resultando ganadora la correspondiente al Puerto de Castellón y obteniendo sendas menciones honoríficas la Delegación de Almería de la Agencia Tributaria y la Dirección Provincial de la Tesorería General de la Seguridad Social en Córdoba (MAP 2002b: 20-24). A la 3. a edición concurrieron catorce organizaciones, resultando ganadoras ex-aequo la Dirección Provincial de la Tesorería General de la Seguridad Social en Valencia y la Delegación de Almería de la Agencia Tributaria. Además, en esta edición las nueve organizaciones que habían superado los 200 puntos EFQM en el proceso de evaluación recibieron los correspondientes Sellos de Excelencia del Club (MAP 2004: 12-13). En la 4. a edición, convocada en noviembre de 2003 y resuelta en octubre de 2004, participaron 11 candidaturas, resultando ganadora la Organización Nacional de Trasplantes y obteniendo una mención honorífica el Departamento de Seguridad de la Presidencia del Gobierno. Posteriormente, dos de las organizaciones candidatas han tramitado y obtenido el Sello de Excelencia en su categoría de Bronce (MAP 2005: 18-19). El gráfico 2 muestra la evolución interanual de la participación en este premio.

${ }^{20}$ Adaptación recogida en las sucesivas ediciones de la Guía de Autoevaluación para la Administración Pública. Modelo EFQM de Excelencia. Madrid: MAP-BOE, 2004, 4. ${ }^{\text {a }}$ ed.

${ }^{21}$ La Presidencia, en las tres primeras ediciones, recayó en el Secretario de Estado para la Administración Pública, y en la cuarta en el Secretario General para la Administración Pública. La composición del resto del Jurado es similar al de Mejores Prácticas. 


\section{GRÁFICO 2}

\section{Evolución de la participación premio calidad}

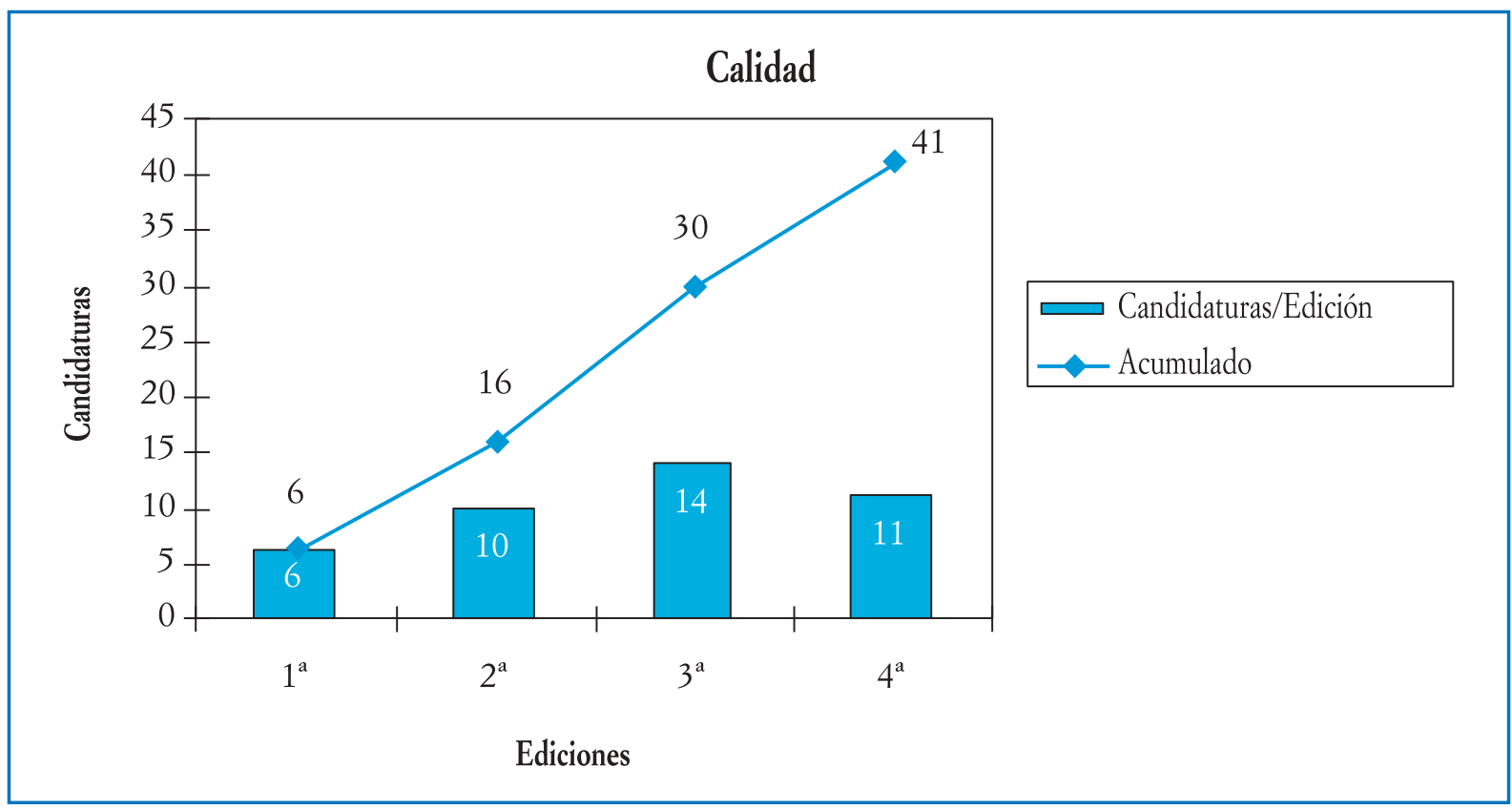

\subsection{Los premios y la práctica de la evaluación}

Las cuatro ediciones celebradas de las dos clases de premios ofrecen un incremento sostenido de la participación en las tres primeras y una inflexión a la baja en la cuarta como muestra el gráfico 3.

\section{GRÁFICO 3}

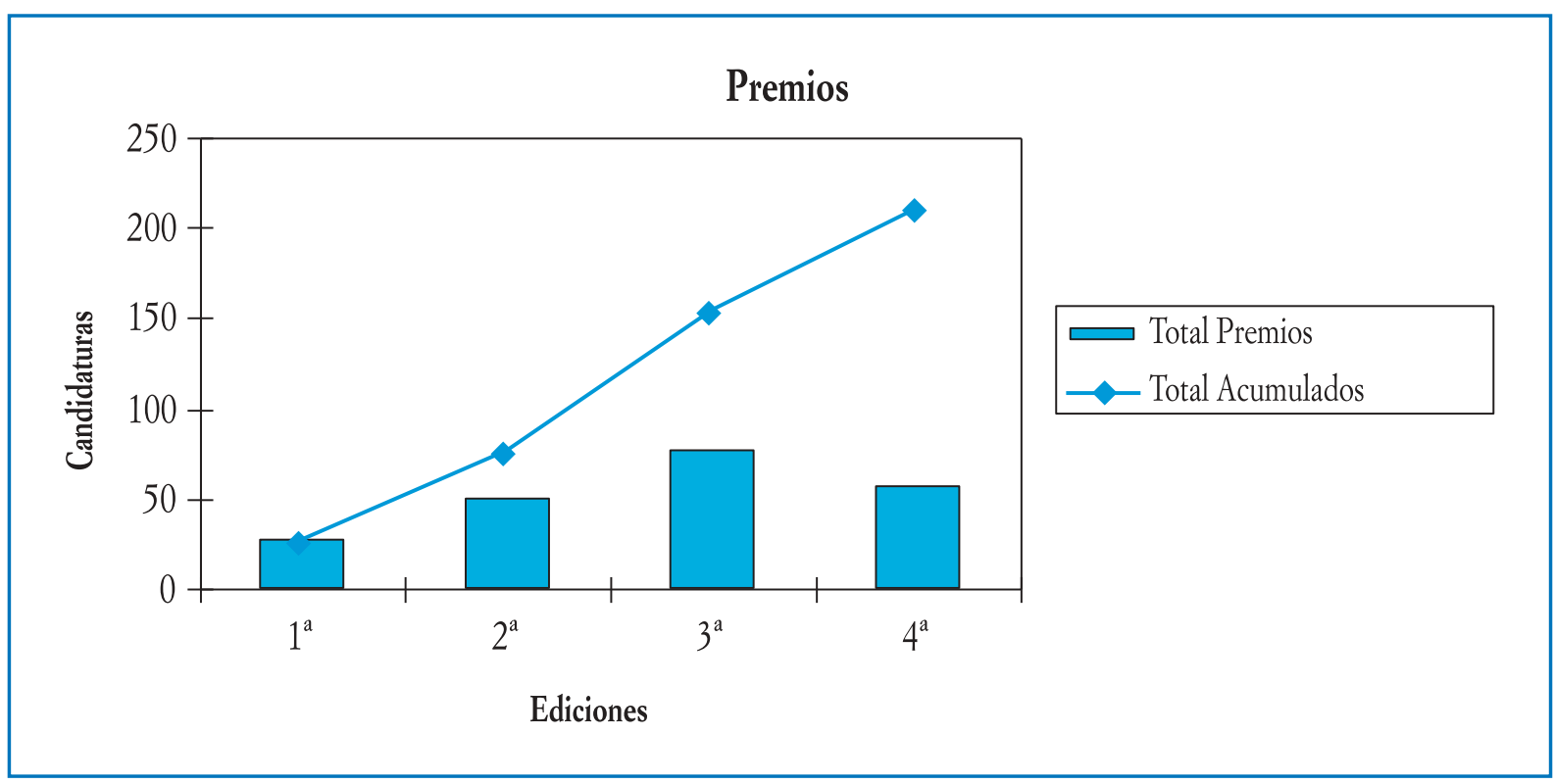


La disminución del 25\% que suponen las 47 candidaturas presentadas en la cuarta edición de los «Premios a las Mejores Prácticas» frente a las 63 de la tercera seguramente tiene su explicación en la coyuntura de «incertidumbre administrativa» en que se produjo la convocatoria, ya que el plazo para presentar las memorias expiraba el 16 de febrero de 2004, fecha marcada por las cercanas elecciones generales ${ }^{22}$.

Por su parte, la participación en el «Premio a la Calidad» también muestra una evolución positiva (4 - 10 - 14 - 11). La disminución del $21 \%$ entre la cuarta y la tercera edición también debe matizarse por los mismos motivos que en el caso de los premios a las mejores prácticas ${ }^{23}$.

Ahora bien, la participación en el concurso no es el único indicador de su éxito, sino que debe correlacionarse con su incidencia en la práctica de la evaluación. Como hemos visto, el «Premio a la Calidad» se evalúa conforme a los criterios del Modelo EFQM de Excelencia, ya que éste no sólo sirve como marco de referencia para la autoevaluación sino también para evaluar externamente el rendimiento de las organizaciones. El Modelo EFQM es una herramienta tanto de autoevaluación como de heteroevaluación y añade la ventaja de posibilitar una bomoevaluación a escala global al operar sobre parámetros comúnmente aceptados y hacerse públicos los datos comparativos y agregados (Ruiz 2005c: 185). La elaboración de una memoria de presentación al Premio, conforme a los mismos requisitos del «Premio Europeo a la Calidad» (EQA) de la EFQM, implica un minucioso ejercicio de autoexamen o autoevaluación de la organización, que posteriormente es sometido al escrutinio de evaluadores externos. Este aspecto de la evaluación externa de las candidaturas es de especial importancia, ya que su rigor e independencia confiere credibilidad y prestigio al premio. Para ello y al amparo del mencionado

\section{GRÁFICO 4}

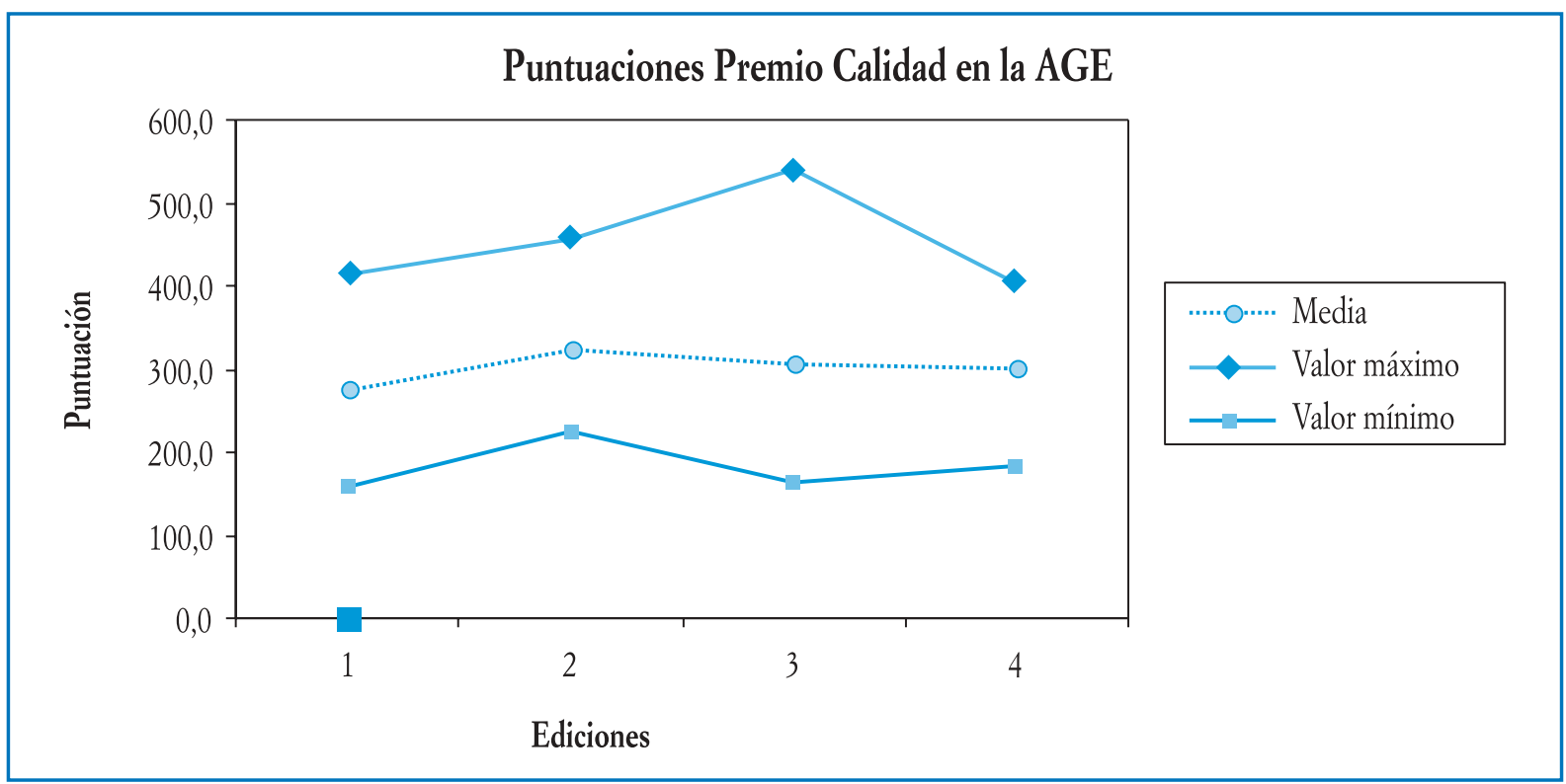

${ }^{22}$ Esta hipótesis puede verse confirmada por el hecho de que inicialmente se presentaron 56 solicitudes de participación, lo que sólo representa una disminución del $11 \%$ con respecto a la 3. a edición.

${ }^{23}$ En el plazo de presentación de solicitudes de participación (15-12-2003) se habían recibido 14 solicitudes, que posteriormente (12-04-2004) no se vieron confirmadas más que por 11 memorias. Por lo tanto, en este sentido cabe decir que no hubo reducción del número de iniciales solicitantes. 
Convenio de Colaboración con el Club Gestión de Calidad, en el periodo 2000-2004 se han formado como evaluadores EFQM 175 funcionarios de la Administración General del Estado, la mayoría de los cuales ha formado parte de los 39 equipos de evaluación, integrados cada uno de ellos por cinco evaluadores, que han intervenido en las cuatro ediciones del premio.

Si la participación, como hemos visto, se incrementó de manera sostenida en las tres primeras ediciones del «Premio a la Calidad» y se estabilizó en la cuarta, cabe decir algo semejante en cuanto a la calidad de las memorias presentadas o, lo que es lo mismo, al grado de excelencia de las organizaciones que describen, ya que las evaluaciones externas realizadas han constatado un incremento general de las puntuaciones obtenidas en cada edición sucesiva, excepto en la última. En el gráfico 4 se comparan las puntuaciones máxima, mínima y media en las cuatro ediciones del premio.

Como puede verse en el cuadro 6, las organizaciones que han recibido el «Premio a la Calidad» han superado en todos los casos los 400 puntos EFQM, aunque debe destacarse que la ganadora en la tercera edición sobrepasó los 500. Estos rangos de puntuaciones son los que permitieron que nueve de las catorce candidaturas presentadas a la 3. a edición obtuvieron además el mencionado «Sello de Excelencia Europea» y que ocho de las organizaciones candidatas a la 4 . $^{\text {a }}$ edición pudieran optar también al mismo.

\section{CUADRO 6}

\section{Detalle de las puntuaciones en el premio a la calidad}

\begin{tabular}{|c|c|c|c|c|}
\hline Puntuaciones & $1 .^{a}$ & $2 .^{\mathrm{a}}$ & $3 .{ }^{a}$ & $4 .^{a}$ \\
\hline Candidaturas & 4 & 10 & 14 & 11 \\
\hline Valor máximo & $>400$ & $>450$ & $>500$ & $>400$ \\
\hline Valor mínimo & $>150$ & $>200$ & $>150$ & $>150$ \\
\hline Media & 273 & 321 & 305 & 293 \\
\hline Desviación típica & 131,6 & 60 & 122 & 76,8 \\
\hline Mediana & 260 & 316 & 299 & 317 \\
\hline
\end{tabular}

La perseverancia en la participación en los premios es un factor clave de éxito y a la vez un claro indicador de la mejora continua experimentada por las organizaciones participantes. Aquellas organizaciones que han concurrido a sucesivas ediciones del Premio han visto incrementadas sus puntuaciones, debiendo destacarse el caso de la Organización Nacional de Trasplantes, única candidatura presente en las cuatro ediciones. Su evolución, como se verá más adelante, es harto significativa al haber transitado desde los poco más de 150 puntos en la 1. ${ }^{a}$ edición a los más de 400 en la 4. . El detalle de las organizaciones que han participado en más de una ocasión en el «Premio a la Calidad» figura en el cuadro 7. 


\section{CUADRO 7}

Organizaciones que ban participado en varias ediciones del premio a la calidad

\begin{tabular}{|l|l|}
\hline \multicolumn{1}{|c|}{ Organización } & Número de candidaturas \\
\hline Tesorería General de la Seguridad Social & 10 \\
\hline Instituto Nacional de la Seguridad Social & 6 \\
\hline Organización Nacional de Trasplantes & 4 \\
\hline Correos y Telégrafos & 4 \\
\hline Agencia Tributaria & 3 \\
\hline Puertos del Estado & 2 \\
\hline Departamento de Seguridad de la Presidencia del Gobierno & 2 \\
\hline Instituto Nacional del Consumo & 2 \\
\hline MAP (Subdelegaciones del Gobierno) & 2 \\
\hline
\end{tabular}

Por su parte, las organizaciones que sólo han concurrido en una ocasión son las siguientes: Subdirección General de Relaciones con la Administración de Justicia y el Ministerio Fiscal (Ministerio de Justicia), Subdirección General de Personal Militar (Ministerio de Defensa), Centro de Formación de la Policía (Ministerio del Interior), Parque Móvil del Estado (Ministerio de Economía y Hacienda), Regionales de RENFE y Aena (Ministerio de Fomento).

Es digno de destacar el caso de las organizaciones de la Seguridad Social. La Tesorería General y el Instituto Nacional de la Seguridad Social son las dos organizaciones que más candidaturas han presentado y acumulan entre los dos 16 de las 41 candidaturas, lo que representa el 39\% del total. El número de galardones obtenidos por ellas asciende a 3, lo que, a su vez, supone el 37,5\% de los concedidos. Si nos referimos a los 11 Sellos de Excelencia tramitados, veremos que 5 (45\%) de ellos lo han sido por estas organizaciones. Sin lugar a dudas, todo esto correlaciona directamente con la introducción desde el año 2000 de la práctica sistemática de la autoevaluación en estas organizaciones, ya que en 2005 el número de unidades de la Seguridad Social que han abordado procesos de autoevaluación asciende a 91, habiendo extendido la Tesorería la autoevaluación a todas sus Direcciones Provinciales y el INSS a 39 de las suyas.

También merece destacarse el caso de las organizaciones dependientes del Ministerio de Fomento con 8 candidaturas repartidas entre Correos y Telégrafos, Puertos del Estado, RENFE y Aena, organizaciones en las que también es práctica habitual la autoevaluación y que disponen de sus propios premios o concursos.

Los datos de participación por ministerios en ambos premios que se detallan en el cuadro 8 son elocuentes acerca de la implicación de las diferentes áreas administrativas, destacando que el 69\% de las candidaturas presentadas a mejores prácticas corresponden sólo a tres de los dieciséis ministerios (Economía y Hacienda, Trabajo y Asuntos Sociales y Administraciones Públicas). Correlativamente, el 67\% de los galardones han recaído en iniciativas de los mismos ministerios. Por lo que respecta al «Premio a la Calidad», el $68 \%$ de las candidaturas pertenecen también al ámbito de tres ministerios (los dos primeros citados anteriormente y el de Fomento), los mismos que se reparten el $75 \%$ de los galardones concedidos. 


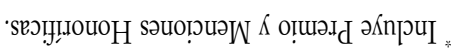

\begin{tabular}{|c|c|c|c|c|c|c|c|c|c|c|c|c|c|c|c|c|c|c|}
\hline $8 /$ It & I & $z$ & $\varepsilon$ & I & II & $\forall I$ & 0[ & 9 & IS/ ILI & ZI & ZI & SI & ZI & $\angle t$ & $\varepsilon 9$ & $0 t$ & IZ & TVLOL \\
\hline & & & & & & & & & & & & & & & & & & INW \\
\hline & & & & & & & & & $/ \mathrm{I}$ & & & & & I & & & & tWW \\
\hline I/ 9 & I & & & & I & $\tau$ & $\tau$ & I & $\varepsilon / 8$ & & & 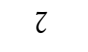 & I & I & & $\varepsilon$ & $t$ & JSW \\
\hline & & & & & & & & & & & & & & & & & & ТกวК \\
\hline$/ 2$ & & & & & & I & & I & L/ IZ & & $\tau$ & $\varepsilon$ & $\tau$ & $t$ & L & 9 & $t$ & d $\forall W$ \\
\hline$I / 2$ & I & & & & I & I & & & $t / 6$ & I & I & & $z$ & I & 9 & & 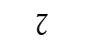 & SEYddW \\
\hline & & & & & & & & & $/ \mathrm{I}$ & & & & & I & & & & VdVW \\
\hline & & & & & & & & & $\mathrm{I} / \mathrm{S}$ & I & & & & $z$ & & $z$ & I & JLIN \\
\hline$\varepsilon / 9[$ & & I & I & I & $\varsigma$ & $t$ & $\varsigma$ & r & SI / 99 & L & $\tau$ & $\varsigma$ & I & $8 \mathrm{~L}$ & $9 z$ & $0 z$ & $\tau$ & SVLW \\
\hline & & & & & & & & & $\varepsilon / t$ & & I & I & I & & 2 & I & I & JAN \\
\hline I/ 8 & & & I & & $\varepsilon$ & 2 & $\tau$ & I & Z/II & & I & & I & $t$ & 9 & & I & WOIW \\
\hline$/ \mathrm{I}$ & & & & & & I & & & $\varepsilon / 8$ & & I & I & I & I & $t$ & $\tau$ & I & LNIN \\
\hline$\tau / t$ & & I & I & & I & 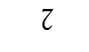 & I & & ZI / I $\varepsilon$ & $\varepsilon$ & $\varepsilon$ & $\varepsilon$ & $\varepsilon$ & II & 6 & 9 & $s$ & $\mathrm{HAW}$ \\
\hline / I & & & & & & I & & & $\mathrm{I} / \varepsilon$ & & I & & & $z$ & I & & & HHAN \\
\hline$/ \mathrm{I}$ & & & & & & & & I & / I & & & & & & I & & & Snfw \\
\hline & & & & & & & & & $/ 2$ & & & & & I & I & & & J甘YW \\
\hline $9 / 3$ & $\mathrm{PH}_{\mathrm{e}}{ }^{\prime} \mathrm{t}$ & 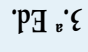 & PA ${ }_{8} \cdot z$ & 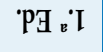 & PG. & 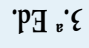 & $\mathrm{PB}_{\mathrm{E}} \mathrm{z}$ & 'PG:I & $9 / 3$ & PG.'t & PA $\ddot{*}_{\varepsilon}^{\prime} \mathcal{E}$ & $\mathrm{PH}_{\mathrm{B}} \mathrm{Z}$ & $\mathrm{PB}_{\mathrm{E}} \cdot \mathrm{I}$ & 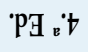 & PG ${ }_{0}^{-} \mathcal{E}$ & PA ${ }^{-} z$ & 'PG ${ }^{\prime} \mathrm{I}$ & о미라빈, \\
\hline 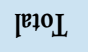 & \multicolumn{4}{|c|}{ 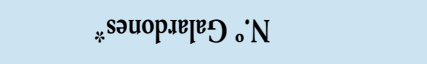 } & \multicolumn{4}{|c|}{ 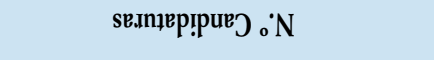 } & {$[\mathrm{p}+10 \mathrm{~L}$} & \multicolumn{4}{|c|}{ 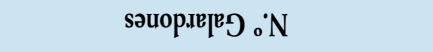 } & \multicolumn{4}{|c|}{ se.mıpp!pue o $^{\circ} \mathrm{N}$} & \\
\hline \multicolumn{9}{|c|}{ बVबITHJ } & \multicolumn{9}{|c|}{ 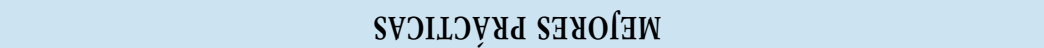 } & \\
\hline
\end{tabular}


El proceso de cada edición del premio no se cierra exclusivamente con el acto público de entrega de los galardones, aspecto éste que refleja el elemento más visible del premio —la formalización del reconocimiento-, sino que el ciclo de la evaluación, desde el punto de vista del aprendizaje y la mejora, se completa con el informe de retroalimentación conteniendo los puntos fuertes y las áreas de mejora identificadas que se facilita a las organizaciones evaluadas, tanto en los «Premios a las Mejores Prácticas» como en el «Premio a la Calidad». En este último se lleva a cabo por parte del equipo evaluador una visita a posteriori a la organización para poner en común las conclusiones del informe y extraer las enseñanzas oportunas de cara a iniciar las acciones de mejora que resulten apropiadas. Los resultados de estas reuniones, junto con los de las encuestas realizadas por la Dirección General de Inspección, Evaluación y Calidad de los Servicios tanto a las organizaciones como a los evaluadores participantes, han permitido a este órgano conocer los problemas en el desarrollo del proceso de gestión de los premios, revisar su actuación e introducir las mejoras consiguientes. Las encuestas realizadas a organizaciones candidatas y a evaluadores ponen de manifiesto un índice de satisfacción con el proceso de los premios que se sitúa en torno a 7,5 sobre 10.

Por otra parte, las organizaciones que han visto galardonadas sus iniciativas en ambas modalidades de los premios tienen la oportunidad de difundir públicamente sus experiencias en la Jornada de la Calidad en la Administración Pública que, en el marco de la Semana Europea de la Calidad, se celebra anualmente en el Instituto Nacional de Administración Pública. Asimismo, para facilitar la socialización y el acceso a las buenas prácticas, el MAP publica un libro memoria de cada edición de los premios conteniendo los resúmenes de las memorias galardonadas, documentos que también se encuentran disponibles en la página de calidad de la web del Ministerio, página que ha sido objeto de más de 65.000 visitas en el periodo enero 2003 - octubre 2005. El reconocimiento a las organizaciones ganadoras no se agota con las medidas señaladas, sino que además se complementa con la oportunidad de presentar sus iniciativas de éxito en las Conferencias de Calidad para las Administraciones Públicas de la Unión Europea que se celebran bienalmente en el país que ostenta la presidencia de turno. Por último, también es una forma de reconocimiento la transferencia real de alguna de las buenas prácticas premiadas, como es el caso de la aplicación informática Caronte para elaborar Cartas de Servicios, por la que el Instituto de Astrofísica de Canarias obtuvo un premio a las mejores prácticas en la segunda edición. Este software, que fue incorporado como CD en la segunda edición de la Guía para la implantación de Cartas de Servicios editada por el Ministerio de Administraciones Públicas, ha sido adoptado por la Subsecretaría de la Función Pública de Méjico y ha sido objeto de interés por parte del Ministerio de Planificación, Presupuesto y Gestión de Brasil.

El reconocimiento y el aprendizaje como consecuencia de la participación en los premios no se limita a las organizaciones candidatas sino que, como es lógico, también afecta a los funcionarios que integran los equipos de evaluación, ya que es éste un proceso recíproco en el que ambas partes aprenden, las organizaciones al recibir la retrolimentación de los evaluadores y éstos al consolidar su conocimiento y habilidades mediente la praxis de la evaluación en contacto directo con aquéllas. Por último, la entrega a los funcionarios que han actuado de evaluadores de un diploma acreditativo supone la posibilidad de incorporar la función evaluadora como un elemento importante en sus curricula profesionales.

Además de los cursos específicos de Evaluación EFQM y elaboración de memorias que, como ya se ha mencionado, se imparten en colaboración con el Club Excelencia en Gestión en cada edición del «Premio a la Calidad», la evaluación de la calidad y excelencia ha pasado a integrar el acervo de los programas docentes en la Administración General del Estado, habiendo recibido este tipo de formación de 1999 a 2005 alrededor de dos mil funcionarios. 


\section{Un caso ejemplar: La Organización Nacional de Trasplantes}

Cualquiera de las ocho organizaciones galardonadas en las distintas ediciones del «Premio a la Calidad en la Administración General del Estado» serviría como ejemplo de los beneficios que reporta la participación en el mismo. No obstante, se ha optado por el caso de la última ganadora, la Organización Nacional de Trasplantes por tratarse de la única que ha participado en todas las ediciones y presenta un ejemplo de perseverancia y mejora paulatina de su rendimiento.

La Organización Nacional de Trasplantes (ONT) es un organismo adscrito al Centro Nacional de Trasplantes y Medicina Regenerativa del Ministerio de Sanidad y Consumo que, bajo los principios de cooperación, eficacia y solidaridad, tiene por misión la coordinación de las actividades de donación, extracción, preservación, distribución, intercambio y trasplante de órganos y tejidos en el conjunto del Sistema Nacional de Salud español. La ONT actúa a modo de agencia de servicios en estrecha colaboración con los coordinadores de trasplantes en los ámbitos autonómicos y hospitalarios, lo que conforma una estructura de coordinación en tres niveles (nacional, autonómico y hospitalario) conocida como Modelo Español de Trasplantes.

En un proceso de mejora continua, la ONT viene aplicando la autoevaluación según el Modelo EFQM de Excelencia para identificar sus puntos fuertes y las áreas de mejora sobre las que actuar. Precisamente la práctica de la autoevaluación EFQM ha permitido a la Organización presentarse consecutivamente a las cuatro ediciones del «Premio a la Calidad en la Administración General del Estado», así como la obtención en 2003 del Sello de Excelencia. La incorporación a la práctica de la autoevaluación EFQM y la participación en los premios ha supuesto para la ONT el complemento a sus logros obtenidos desde el comienzo de su singladura en 1989 y que ha llevado al Modelo Español de Trasplantes a recibir el reconocimiento de las más altas instituciones europeas y americanas. Congruente con todo ello, el jurado de la IV edición del «Premio a la Calidad en la AGE» acordó valorar muy positivamente y expresar su reconocimiento a la Organización Nacional de Trasplantes por su perseverancia al haber concurrido a las cuatro ediciones del premio y por el avance mostrado en este recorrido, avalando desde la perspectiva de la Excelencia su liderazgo internacional en el ámbito de los trasplantes, y proponer, en consecuencia, al Ministro de Administraciones Públicas la concesión del «Premio a la Calidad» en su IV edición a la Organización Nacional de Trasplantes (MAP 2005).

Efectivamente, este galardón culmina un proceso que se inicia con la participación de la ONT en la 1. ${ }^{a}$ edición tanto del «Premio a la Calidad» como de los «Premios a las Mejores Prácticas». En estos últimos recibió uno de los premios por su Programa de garantía de calidad del proceso de donación, extracción y trasplante de órganos y tejidos. Su participación simultánea en el Premio a la Calidad no se saldó, en cambio, con un galardón, ya que era la primera vez que la organización se sometía a una evaluación EFQM. Así, la memoria presentaba, por ejemplo, un claro desequilibrio entre la gran atención prestada a los resultados y la escasa a los agentes facilitadores. Aunque se mostraba una tendencia positiva de más de cinco años en los resultados clave (criterio 9a) y con comparaciones favorables a escala internacional, no se evidenciaba relación de causalidad entre tales resultados y las acciones llevadas a cabo en los agentes facilitadores. En resumidas cuentas, la memoria ponía de manifiesto ciertos puntos fuertes sobre todo en lo que se refiere al logro de resultados, derivados del Programa de Garantía de Calidad (recordemos, práctica premiada), pero en general denotaba cierta confusión conceptual y escasa familiaridad con el Modelo EFQM.

La ONT volvió a participar en la 2. ${ }^{\text {a }}$ edición de los premios, obteniendo de nuevo un galardón en los de mejores prácticas por su iniciativa Gestión de alarmas de donación, mientras que casi duplicaba su puntuación en el de Calidad al haber corregido deficiencias detectadas en el ciclo anterior y mejorado notablemente sus procesos (criterio 5) y sus resultados en los clientes (criterio 6). 
La ONT no concurrió a la 3. ${ }^{\text {a }}$ edición de los «Premios a las Mejores Prácticas», aunque sí a la del «Premio a la Calidad». La memoria presentada a éste mostraba cierta estabilización, con un ligero incremento del 9\% en la puntuación global. En este sentido, puede afirmarse que la ONT se hallaba en la meseta de las organizaciones que empiezan a interiorizar la excelencia en su gestión.

En la 4. a edición de los «Premios a las Mejores Prácticas» presenta otra vez la organización una candidatura, en esta ocasión la referida al sistema informático de gestión de su procedimiento de donación, denominada GesONT, que no resultó premiada. En cambio, la candidatura presentada al Premio a la Calidad, como hemos visto, obtuvo finalmente recompensa. Tras cuatro años de experiencia, el equipo evaluador pudo identificar una serie de puntos fuertes relacionados con la implicación de los líderes de la organización en los programas de calidad, la implantación de la norma ISO 9001:2000 o el enfoque claro y sólidamente fundamentado de un sistema de alianzas coherentemente alineado con la Política y la Estrategia de la organización. La ONT incrementa su puntuación en todos los criterios de evaluación y consolida sus buenas puntuaciones anteriores en los criterios de mayor ponderación como son Procesos, Resultados en los clientes y Resultados clave. La puntuación global se incrementa en un $23 \%$ con respecto a la anterior y se coloca en el rango del Reconocimiento a la Excelencia de los Levels of Excellence de EFQM.

\section{Nuevas perspectivas}

En el seno del III Encuentro sobre Administración y Calidad de los Servicios en Castilla y León, celebrado en Segovia en marzo de 2001, tuvo lugar una reunión interadministrativa en la que participaron responsables de la Administración General del Estado, de la Junta de Castilla y León, del Principado de Asturias, de la Junta de Comunidades de Castilla-La Mancha, de la Xunta de Galicia, de la Comunidad de Madrid, de la Región de Murcia, de la Diputación General de Aragón, de la Diputación Regional de Cantabria y de la Federación Regional de Municipios y Provincias. Estos responsables suscribieron una declaración postulando la conveniencia de crear un premio nacional a la calidad abierto a las distintas administraciones públicas. Desde entonces, la creación de un premio de tales características ha constituido una especie de asignatura pendiente y así se puso de manifiesto en el Acto de Entrega de la IV Edición de los «Premios a la Calidad y a las Mejores Prácticas en la Administración General del Estado», celebrado el 10 de noviembre de 2004. En este sentido, el Ministro de Administraciones Públicas hizo énfasis en la necesidad de que la administración pública española respondiera mejor al modelo territorial de la Constitución, con el establecimiento de relaciones horizontales basadas en el diálogo y la cooperación entre todas las administraciones del Estado, anunciando, en este contexto, la intención de ampliar el ámbito de los premios con el objetivo último de poder crear un premio nacional a la calidad en las administraciones públicas españolas (MAP 2005). Este anuncio hizo que no se convocara la 5. a edición de los premios del MAP y que se concentraran los esfuerzos en la creación del premio «nacional». Así, el Real Decreto 951/2005 de 29 de julio, por el que se establece el marco general para la mejora de la calidad en la Administración General del Estado, ha instituido los «Premios a la Calidad e Innovación en la Gestión Pública». El marco general para la mejora de la calidad integra una serie de programas básicos (Analísis de la demanda y evaluación de la satisfacción de los usuarios, Cartas de Servicios, Quejas y sugerencias, Evaluación de las organizaciones, Reconocimiento y Observatorio) que recorren todo el ciclo de la gestión, desde las actividades de planificación y diseño hasta las de evaluación, mejora y reconocimiento. El capítulo VI de esta norma establece dos formas de reconocimiento íntimamente relacionadas con el programa de evaluación de las organizaciones. Por una parte, la certificación y concesión de un sello de excelencia a aquellas organizaciones que se hayan autoevaluado conforme a modelos de gestión de calidad de referencia y sometido sus resultados a la correspondiente validación externa. Por otra, los premios, concebidos como una forma más de reconocimiento de las organizaciones que contribuye a la mejora de la calidad y la innovación 
en la gestión pública. Así, el artículo 24 establece que los premios están destinados a reconocer y galardonar a las organizaciones públicas que se hayan distinguido en alguno de los siguientes ámbitos:

- La excelencia de su rendimiento global por comparación a modelos de referencia reconocidos.

- La innovación en la gestión de la información y del conocimiento, así como de las tecnologías.

- La calidad e impacto de las iniciativas singulares de mejora implantadas.

Estos premios están abiertos a la participación voluntaria de las organizaciones de la Administración General del Estado, de las administraciones de las comunidades autónomas, de la Administración local y de las ciudades de Ceuta y Melilla, así como a otros entes de derecho público.

Los «Premios a la Calidad e Innovación en la Gestión Pública» se conciben a modo de un sistema que integra diversos tipos y que parte de la premisa de aprovechar las experiencias existentes. El núcleo originario de los nuevos premios está constituido por los anteriores premios en la Administración General del Estado, es decir, el «Premio a la Calidad», ahora denominado «Premio a la Excelencia», y los «Premios a las Mejores Prácticas», ahora llamados «Premios a las Buenas Prácticas». Estos últimos se desdoblan en dos categorías: iniciativas de mejora en la gestión interna e iniciativas con impacto externo en los ciudadanos/usuarios, que recoge el acervo del conocido «Premio Ciudadanía». La tercera modalidad de los premios, Innovación en la gestión de la información y del conocimiento así como de las tecnologías, pretende dar respuesta al protagonismo que ha alcanzado la dimensión innovadora para las organizaciones. En el caso de las tecnologías o administración electrónica, se aprovecha también la existencia de un premio en este campo, Tecnimap, incorporándolo al sistema de premios. Téngase en cuenta que a lo largo de las cuatro ediciones de los premios a las mejores prácticas en la AGE, la proporción de iniciativas candidatas de carácter tecnológico o informático ha sido muy elevada. Al reconducirlas al premio Tecnimap se evitan posibles duplicidades entre los premios a la innovación y los premios a las buenas prácticas.

De los tres ámbitos de los premios, cuyas bases se han desarrollado por Orden del Ministerio de Administraciones Públicas, de 14 de febrero de 2006, debe subrayarse, desde el estricto punto de vista de la homogeneidad y trazabilidad de la evaluación, el de Excelencia, ya que se prevé como requisito para presentarse al mismo el que las organizaciones candidatas hayan desarrollado procesos de autoevaluación y que las candidaturas serán evaluadas según los criterios del Modelo EFQM²4.

\section{Conclusiones}

Los premios a la calidad y excelencia constituyen hoy día una realidad ampliamente extendida y arraigada en la generalidad de los países, tanto en el sector privado como en el público. Los programas de premios a la calidad y excelencia tienen por finalidad el reconocimiento explícito al buen rendimiento y a los esfuerzos de mejora de las organizaciones. En este sentido, han mostrado claramente su utilidad como instrumento de motivación, así como de socialización de buenas prácticas y de fomento de la emulación. En el sector público, suelen contemplarse dos tipos de premios; por un lado, los que están destinados a promover la máxima participación posible así como a iniciar a las organizaciones menos avanzadas en la cultura de la calidad, y, por otro, los que, de forma más «selectiva», están dirigidos a organizaciones familiarizadas con la gestión de calidad, promoviendo la utilización de modelos de excelencia que permitan la comparación y el aprendizaje sobre bases comunes. Los premios tienen

${ }^{24}$ Por órdenes de 17 de octubre y 20 de diciembre de 2006 se han concedido los Premios a su Calidad e Innovación en la Gestión Pública en sus modalidades Excelencia, Ciudadanía y Buenas Prácticas de Gestión Interna. 
un carácter pedagógico y, en este sentido, es conveniente la existencia de los dos tipos de premios, para proyectos y para organizaciones. Las iniciativas parciales de mejora - proyectos- constituyen un primer estadio en el proceso continuo de la calidad, que permite a las organizaciones ir avanzando hasta los niveles que las hacen susceptibles de someterse a evaluaciones de su excelencia. La pedagogía de los premios no se circunscribe a las organizaciones que, al concurrir a los mismos, son evaluadas, sino que se extiende asimismo a los propios evaluadores que fortalecen su conocimiento en la praxis de la evaluación.

En las Administraciones públicas españolas se vienen generalizando en los últimos años los programas de premios, tanto en distintas Comunidades Autónomas como en la Administración General del Estado, con una notable convergencia en cuanto a planteamiento, finalidad y sistemas de evaluación. El crecimiento de la participación en estas iniciativas ha sido sostenido, si bien a veces ha podido verse afectado por los cambios (o por las expectativas de cambio) en el nivel político, lo que refuerza la necesidad de hacer énfasis en el liderazgo perseverante en las organizaciones públicas. En cualquier caso, el mantenimiento de la participación a lo largo de varios ciclos contribuye claramente a la mejora y la elevación del nivel de excelencia de las organizaciones.

La experiencia muestra, por otra parte, que los programas de premios guardan una estrecha correlación con la práctica de la autoevaluación organizacional. Si los premios emplean para evaluar las candidaturas modelos de referencia consolidados juegan un papel de primer orden para fomentar la autoevaluación. Debidamente institucionalizados, constituyen un complemento y una forma de promoción de la autoevaluación, ya que hacen visibles las consecuencias de la misma y permiten un escrutinio externo de la excelencia de las organizaciones, combinando así dos elementos clave para implantar con éxito la cultura de la evaluación y la gestión de calidad, cuales son la voluntariedad en la participación y la institucionalidad que hace visible el compromiso de los decisores políticos.

Los aspectos de marketing no son meramente accesorios en la institucionalización de los programas de premios. Por el contrario, el éxito de los premios y, aún más importante, su incidencia en el arraigo de la cultura de la evaluación depende en gran parte de la adopción de adecuadas medidas de difusión pública (actos, jornadas, conferencias, acciones formativas, publicaciones impresas, páginas web, etc.).

La creación de una estructura «estatal» 0 «nacional» de premios que vertebre las iniciativas de esta naturaleza desarrolladas en los distintos niveles de gobierno supone una oportunidad para facilitar, junto con otras medidas, la constitución de un sistema público de evaluación en España, finalidad que persigue la Agencia Estatal de Evaluación de las Políticas Públicas y la Calidad de los Servicios.

\section{REFERENCIAS BIBLIOGRÁFICAS Y DOCUMENTALES}

Engel, C. (2003), Quality Management Tools in CEE Candidate Countries. Current Practice, Needs and Expectations. Maastricht: EIPA.

Löffler, E. (1996), La modernización del sector público desde una perspectiva comparativa: conceptos y métodos para evaluar y premiar la calidad en el sector público en los países de la OCDE. Madrid: INAP.

Löffler, E. (2001), «Quality Awards as a Public Sector Benchmarking Concept in OECD Member Countries: Some Guidelines for Quality Awards Organizers», Public Administration and Development, 21: 27-40.

MAP (2000), Libro Blanco para la Mejora de los Servicios Públicos. Madrid: MAP.

MAP (2002a), Premios a la Calidad y a las Mejores Prácticas en la Administración General del Estado. I Edición. Madrid: MAP. MAP (2002b), Premios a la Calidad y a las Mejores Prácticas en la Administración General del Estado. II Edición. Madrid: MAP. 
MAP (2003), La Administración al servicio del ciudadano europeo. Encuesta relativa a las actividades de calidad de los Estados miembros de la Unión Europea. Madrid: MAP.

MAP (2004), Premios a la Calidad y a las Mejores Prácticas en la Administración General del Estado. III Edición. Madrid: MAP.

MAP (2005), Premios a la Calidad y a las Mejores Prácticas en la Administración General del Estado. IV Edición. Madrid: MAP.

Ruiz, J. (2003), «Metodologías de calidad: la experiencia de la Administración General del Estado (España)», en La calidad en los servicios públicos administrativos, Santiago de Compostela: EGAP/IGAP.

Ruiz, J. (2005), «El liderazgo directivo en los modelos de excelencia», en Natera, A. y Vanaclocha, F.J. dir., Los liderazgos en el mercado político y la gestión pública. Madrid: Universidad Carlos III y BOE.

Ruiz, J. (2005). «Adaptación del Modelo Iberoamericano a la Administración Pública». Ponencia presentada en el X Congreso del CLAD, Santiago de Chile, 18-21 octubre 2005.

Ruiz, J. (2005), «La calidad de los servicios en el contexto general de la evaluación en la administración pública española», en Garde, J.A. coord., La Agencia Esatal de Evaluación de la Calidad de los Servicios y de las Políticas Públicas. Madrid: INAP.

Ruiz, J. (2004) coord., Guía de Autoevaluación para la Administración Pública. Modelo EFQM de Excelencia. Madrid: MAP-BOE.

Ruiz, J. y Corces, A. (2003), Guía de Autoevaluación para la Administración Pública. Modelo Iberoamericano de Excelencia en la Gestión. Madrid: MAP-FIIAPP.

Vanaclocha et al. (2005), «Algunas referencias sobre metodología de la evaluación de las políticas y los servicios públicos», en Garde, J.A. coord., La Agencia Estatal de Evaluación de la Calidad de los Servicios y de las Políticas Públicas. Madrid: INAP. 